\title{
Cultivating connection in the classroom
}

\section{GinevraClark®}

\section{The world is facing multiple unfolding global crises and chemistry systems are integral in both the cause and solution to these challenges. Systems thinking can be used not only to support student learning of chemistry concepts, but also to build community within and beyond the classroom.}

Systems thinking describes a set of strategies to understand how parts of a system interact and can be applied to human systems, chemical systems or both simultaneously ${ }^{1}$. The UN Sustainable Development Goals (UNSDGs) provide interconnected benchmarks to address global challenges from climate change to world hunger. Hence, the holistic perspective provided by systems thinking is considered essential for achieving the UNSDGs. To address these issues in the future, the students of today need opportunities to connect global issues, fundamental science concepts and their personal experience. What happens in the classroom needs to rise above the din of twenty-first century life, where seemingly disconnected crises follow in rapid and overlapping succession. Preparing students for the future means not just connecting ideas, but supporting students to build a network of people and communities. Here, I share several examples of teaching focused on building connection in the classroom to prepare students to address global challenges.

\section{Developing a holistic science identity} Within the classroom, it is a challenge to connect students, connect with our students and connect with the outside community. However, this type of academic integration is essential for retention of underrepresented groups ${ }^{2}$. It is no coincidence that this challenge relates to the UNSDGs number 5 (gender equality) and number 10 (reducing inequalities).

In Carlone's seminal work on women of colour in science, recognition was noted as the key element for students to develop a science identity ${ }^{3}$. Successful women of colour who were not recognized within the scientific community often built an "altruistic science identity" exclusively within the health sciences ${ }^{3}$. This separation between altruism and science is unhealthy for the science disciplines and its participants, leading to fractured identities and driving researchers away to find wholeness. Systems thinking strategies can broaden the definition of what it means to be a scientist, allowing for altruistic identities to thrive. Thereby, opportunities are presented for students to see themselves as a scientist capable of enacting change. Recognition can only be accomplished by connecting to other people, not just through ideas.

\section{Moving beyond individualistic ideas Addressing global challenges means} recognizing how system components interact, in addition to developing stronger, synergistic relationships between interacting parts of a system. The development of these relationships can transition linear, incremental change to exponential growth. For example, on one hand, recycling is often dismissed as an individual effort that doesn't pay off. By contrast, zero waste communities drive a cultural shift towards recycling and additional forms of waste reduction. The shift away from consumerism and individual effort towards communal action is a possible precursor to cultural transformation, which ultimately puts pressure on corporations and policymakers to shift course as well.

We need a similar cultural transformation in education that goes beyond individualistic educational goals to elevate the classroom and community. Students need to see themselves and their growth as part of a system that is connected to and sustained by their communities. This type of social integration has always been essential to broadening participation, but with remote or hybrid education, the problem of students losing interest and not participating has become universal. While retention is a complex problem, research on social integration suggests that "students chose to persist when they perceive intellectual and social congruence, or a normative fit between the students and the values, social rules, and academic quality of the social community"2. A systems thinking approach may support students by not only increased opportunity for academic integration, but also by incorporating more complex, value-oriented activities. Such activities are demonstrated to increase retention of underrepresented student populations ${ }^{4}$.

A simple and tangible example to support academic integration in the classroom is by well-considered group presentations ${ }^{4}$. In this case, not only are students co-creating their understandings, but the presentations inform the class about advanced topics and provide opportunities for students to formulate ideas about these topics. Online communication brought on by COVID-19 has greatly facilitated this approach in moderately sized classrooms (that is, 150 students). In our analytical chemistry course, students create videos and share them on the classroom website. Specifically, the students are given several advanced topics to choose from, which they are required to relate to at least two UNSDGs and propose pathways to address the UNSDGs. Students are also required to watch and comment on at least three of their classmates' videos. This provides students an opportunity to gain perspective on the diversity of connections and solutions offered to UNSDGs and gain recognition for their ideas. It drives learning beyond the classroom and supports deeper connections between students.

\section{Connecting within the scientific discipline} A systems thinking approach supports students by seeing science as a connected whole rather than a series of unconnected facts ${ }^{1}$. For example, a recent publication incorporates the Flint, Michigan (USA) water crisis into a series of activities for analytical chemistry ${ }^{5}$. 


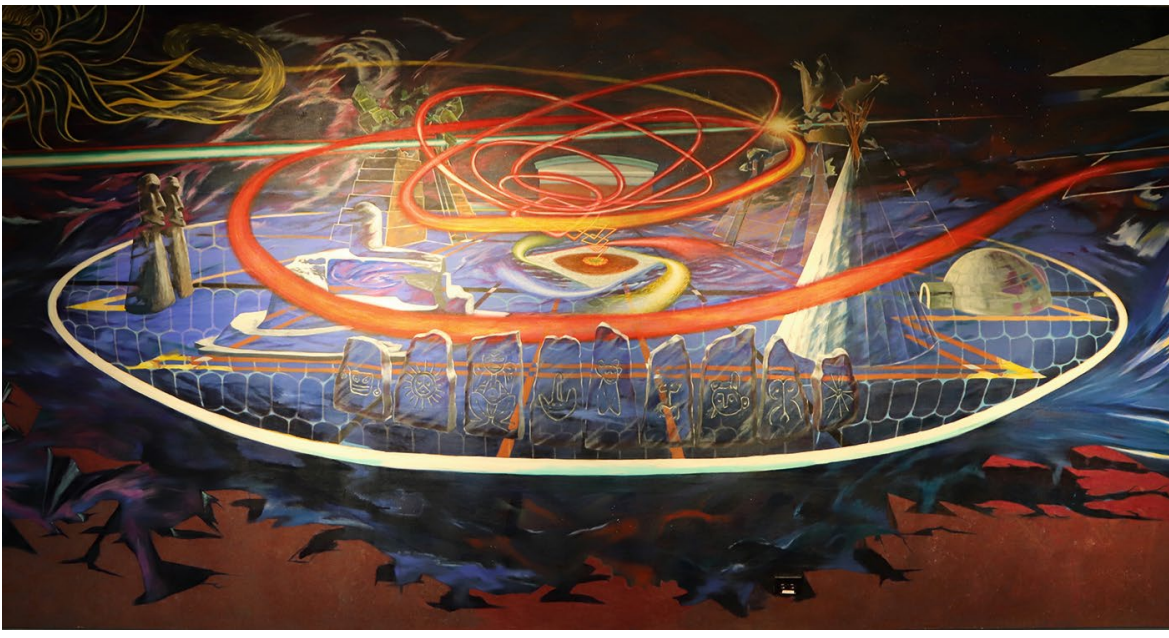

Fig. 1 | The Awakening of the Americas mural. Credit: Rafael Cintrón Ortiz Latino Cultural Center at University of Illinois, Chicago.

The exercises cover a variety of curricular topics from solubility, acid/base chemistry, systematic equilibrium, and use of modelling software. It also includes a laboratory activity and discussion on environmental equity and racism. These efforts are intended to support a cohesive map in students' minds of related topics, allowing students to focus on particular issues analytically, then zoom out to see the bigger picture.

Another approach to allow a future-oriented view of scientific concepts is to ask scientists to share their research with our class. The students use the references from these presentations, as well as features in the textbook to prepare their own presentations. Because all of the basic lecture material is pre-recorded, we can use live class time to work on complex, real-world problems. In our implementation, presentations replace some of the traditional exams. This trade-off aligns with the course objectives, which emphasize the critical thinking and communication over computational aptitude.

\section{Integrating cultural competence and social justice}

We recently reported on a chemistry urinalysis lab that discussed the role of racism in maternal health ${ }^{6}$. Two keys to success in this project were developing a robust framework for culturally relevant education and engaging with social partners who supported us in developing relevant connections. This project emerged from a more general effort to make chemistry relevant. Through this project, we were confronted with the ways racism impacts healthcare; real-life applications inevitably reflect our society and have connections to discrimination, but also to people who address disparity through improved patient care ${ }^{6}$ or other means (such as scientific research or activism).
More recently, we partnered with the Latino Cultural Center (LCC) at University of Illinois, Chicago to incorporate environmental justice dialogues into our science coursework. The dialogues highlight the Just Transition framework, which is a vision for societal change in moving from an extractive to regenerative society, where the "transition itself must be just and equitable; redressing past harms and creating new relationships of power for the future" 7 .

Inside the LCC is a mural called Hub for Social Change, (FIG. 1) which represents the LCC, and by extension, the university as a place for both cultural transformation and societal advancement. In order for the chemistry classroom to fulfill its role, it must reach out to create connections. For example, a guest speaker - a researcher in energy storage - was questioned on how the principles of just transition (a fair and sustainable shift to net zero) impact their work. This discussion fostered a connection between the speaker and the LCC. The simple connections students make are just as important, such as when students discover they are from the same town or connect with a study partner. Chicago community activist Rudy Lozano said “There are no great men or women in this world, only challenges ordinary people must take on"8. To prepare students for these challenges, educators must foster new connections - not only to ideas - but between "ordinary people" - scientists, non-scientists, leaders, global citizens, all alike.

\section{Our cultural journey}

Systems thinking is about more than traversing known connections, it is about exploring and creating new ones. It is about a just transition from an old way of teaching to a new way. The transition itself must involve the participation of cultural partners and the broader scientific community, or it is not just.

There is a consistent message within the chemistry education literature that we can do a better job of teaching fundamental chemistry concepts, engaging our students, and addressing systemic inequities that serve to maintain the status quo. Doing so means moving beyond the traditional borders of the discipline. In addition to the examples provided of incorporating social justice dialogues, connections may be fostered by asking students to share their "cultural journey" This approach was recently reported in the context of an organic chemistry classroom ${ }^{4}$. The connections between chemistry and society are not well-defined, and we need to forward together. Effort must be placed into building connections through collaboration and community building.

Ginevra Clark (D)

Department of Chemistry, University of Illinois,

Chicago, IL, USA.

e-mail:ginevra@uic.edu

https://doi.org/10.1038/s41570-022-00370-0

Mahaffy, P. G., Krief, A., Hopf, H., Mehta, G. $\&$ Matlin, S. A. Reorienting chemistry education through systems thinking. Nat. Rev. Chem. 2, 0126 (2018).

2. Deil-Amen, R. Socio-academic integrative moments: rethinking academic and social integration among two-year college students in career-related programs. J. Higher Educ. 82 54-91 (2011).

3. Carlone, H. \& Johnson, A. Understanding the science experiences of successful women of color: science identity as an analytic lens. J. Res. Sci. Teaching 44, 1187-1218 (2007).

4. White, K. N., Vincent-Layton, K. \& Villarreal, B. Equitable and inclusive practices designed to reduce equity gaps in undergraduate chemistry courses. J. Chem. Educ. 98, 330-339 (2021).

5. Buckley, P. \& Fahrenkrug, E. The Flint, Michigan water crisis as a case study to introduce concepts of equity and power into an analytical chemistry curriculum. J. Chem. Educ. 97, 1327-1335 (2020).

6. Clark, G. A. et al. Urinalysis and prenatal health: evaluation of a simple experiment that connects organic functional groups to health equity. J. Chem. Educ. 97, 48-55 (2020).

7. Just transition: A framework for change. Climate Justice Alliance https://climatejusticealliance.org/ just-transition/ (accessed 4 January 2021).

8. Pineda, P. R. in Rudy Lozano: his life, his people 3 (Taller de Estudios Comunitarios, 1985).

\section{Acknowledgements}

The author thanks Daniel Morales-Doyle, Rosa Cabrera, Ingo Eilks, and Ragnhild Dragøy Whitaker for supportive feedback.

\section{Competing interests}

The author declares no competing interests.

\section{RELATED LINKS}

Hub for social change: https://latinocultural.uic.edu/ murals-exhibits/awakening-of-the-americas-mural/ "Just transition" framework: https://climatejusticealliance.org/ just-transition/

UN Sustainable Development Goals: https://sdgs.un.org/goals 